Egypt. Acad. J. Biolog. Sci., 10(1): 13- 25 (2018)

Egyptian Academic Journal of Biological Sciences

D. Histology \& Histochemistry

$2090-0775$

www.eajbs.eg.net

\title{
Histopathological Changes in the Muscle of the Desert Locust, Schistocerca gregaria (orthoptera: acrididae)Treated with Insect Growth Regulator (IGR), Lufenuron
}

\author{
Fatimah A. M. Al-Zeeb ${ }^{1}$; Essam H. Ibrahim ${ }^{1 \& 2}$ and Reda F. A. Bakr ${ }^{3 \& 4}$ \\ ${ }^{1}$ Biology Department, Faculty of Science, King Khalid University, P.O. Box 9004, \\ Abha 61413, Saudi Arabia. \\ ${ }^{2}$ Blood Products Quality Control and Research Department, National Organization for \\ Research and Control of Biologicals (NORCB), Cairo, Egypt. \\ ${ }^{3}$ Department of Biology, Faculty of sciences, University of Bisha, KSA \\ ${ }^{4}$ Department of Entomology, Faculty of sciences. Ain Shams University \\ E,Mail.: dreem9404@hotmail.com
}

ARTICLE INFO

Article History

Received: $1 / 4 / 2018$

Accepted: 2/6/2018

Keywords:

Toxicity

Histopathological change

Desert locust

IGR

Lufenuron

\section{ABSTRACT}

The present study aimed to minimize the pollution effects of traditional insecticides on the environment by development and synthesis of bio-insecticide and to evaluate insect growth regulators, Lufenuron as insecticidal agents. Stock colony of Schistocerca gregaria was used in this study which were kept in cages and fed on leaves of Castor plant. Treatment of the fifth nymphal instar of locusts by using insect growth regulator, Lufenuron were carried out.

Results showed that, the treatment with different concentrations of Lufenuron (50, 75 and $100 \mathrm{ppm}$ ) resulted in nymphal mortality of $0.0,12.33$ and $21.01 \%$ respectively and percentages of adult malformed with $89.99,73.34$ and 72.33 respectively comparing with control. The current study showed that Lufenuron caused malfunction and decomposition of the components in the muscles of the desert locust.

\section{INTRODUCTION}

The desert locust (Schistocerca gregaria) is a wide spread pest that cause untold and terrible damages to our crop plants in the field. S. gregaria is a species of locust discovered by Forskal in 1775 and considered to be S. Americana gregaria (Dirsh, 1974). $S$. gregaria was generally recognized as polyphytophagos acridid that causes damage to pastures and crops during the desert locust upsurge in 2004 (Tarai and Doumandji, 2009). The preference of food by grasshoppers is determined by many factors such as toughness of the leaf, hairs and water content frequently are believed to influence feeding behavior, chemical differences are also vital, sugars phospholipids, organic nitrogen compound, tannins, and others influence host preference; generally feeding is limited to temperature between $15^{\circ} \mathrm{C}$ and $30^{\circ} \mathrm{C}$ and little time is spent in feeding approximately $15 \%$ (Uvarov, 1977).

Desert locust feed on all sorts of plants; consuming approximately equivalent of their body mass each day. Nearly all crops and non-crops plants are at risk including millet, rice, sorghum, maize, sugar cane, badly, cotton, fruit trees, vegetable, grasses, alacia pines and banana (OECD, 2004). 
Desert Locust has been reported to feed on more than 400 species of plants (Uvarov, 1977).

Chitin synthesis inhibitors (CSIs) interfere with chitin biosynthesis in insects (Gijswijt et al., 1979) and thus prevent moulting or produce an imperfect cuticle (Hammock and Quistad, 1981). These compounds are effective suppressors of development for the entire life cycle on insects (Verloop and Ferrell, 1977). However, these compounds, also, affect the hormonal balance in insects, thereby resulting in physiological disturbances, such as inhibition of DNA synthesis (DeLoach et al., 1981); alteration of carbohydrates (Ishaaya and Ascher, 1977); increase in phenyoxidase activity (Deul et al., 1978); cuticular lipids (Salama et al., 1976) and microsomal oxidase ( $\mathrm{Yu}$ and Terriere, 1977).

However, the histopathological and/or ultrastructural changes in some insect species had been investigated by some CSIs such as Dimilin against Locusta migratoria (Clarke et al., 1977), Pectinophora gossypiella (Saad et al., 1985), Chironomus decorus (Pelsu, 1985), Musca domestica (Bakr, 1986), Culex pipiens (Bakr et al., 1997) and Spodoptera exigua (Younes et al., 2000); triflumuron against $C$. decorus and Tanypus grodhaus (Pelsu, 1985) and Tribolium castaneum (Parween, 1997); buprofezin against Trialeurodes vaporiorum (De Cock and Degheele, 1991).

IGRs represent the newest of all approaches to operational and commercial insect control. Their species or stage-specificities that were higher than those of conventional insecticides offer a good alternative for a selective insect pest control that is in harmony with existing I PM programs. IGRs generally have a good margin of safety for most non-target biota including invertebrates, fish, birds, and other wildlife. They are relatively safe for human beings and domestic animals (Siddall, 1976).

Locust flight muscles are the most active known muscles which are suited for sustaining the prolonged muscular activity of locust

The present work is an attempt to evaluate the toxicity of IGR (Lufenuron) against fifth nymphal instar of $S$. gregaria as well as to study the fine structure of flight muscles after treatment with $\mathrm{LC}_{50}$ of the tested compound. In addition, the study aimed to minimize the pollution effects of the traditional insecticides on the environment by the development and synthesis of bio-insecticide.

\section{MATERIALS AND METHODS Toxicology Evaluation:}

The stock colony of Schistocerca gregaria was provided from the Locust Research Department, Plant Protection Research Institute, Agricultural Research Center, Dokki, Giza. The insects were reared and handled under the following technique described by Abbassi et al. (2003).

Leaves of Castor plant (Ricinus communis) were daily placed as feeding material. The cages were incubated in a constant room temperature $\left(32 \pm 2^{\circ} \mathrm{C}\right)$ and $(30-50 \%$ $\mathrm{RH})$.

The experimental nymphs were segregated from the gregarious stock colony at the beginning of the first nymphal instar and held up in cages $(30 \times 30 \times 30 \mathrm{~cm})$ in diameter. The cages were a wooden farmed equipped with zinc bottom covered by thin layer of sand, glass covered sides and a wiregauze top provided with a little door. Unconsumed food, dead locusts and faces were removed daily.

The whole cage was thoroughly washed and effectively sterilized with 
an antiseptic agent (every 4-6 weeks) or whenever it becomes empty or at the end of any experiment.

One of the insect growth regulators (IGRs) Lufenuron (EC) $10 \%$ was used.

\section{Treatment of Experimental Insects:}

Both sexes of nymphs of one-day old of the $5^{\text {th }}$ nymphal instars of $S$. gregaria during synthesis and deposition of the newly adult cuticle (Taha and El-Gammal 1990) were treated by feeding technique with one of insect growth regulators, the Lufenuron as follows: leaves of Ricinus communis were dipped in 50, 75 and $100 \mathrm{ppm}$ of the Lufenuron for two minutes, then leaves were air dried before being offered to the nymphs for feeding on it. Three replicates of 20 nymphs were subjected to each of the treated leaves. After feeding for 24 hours on the treated leaves, alive nymphs were transferred onto untreated leaves and left to feed for additional 24 hours, after that mortality counts or malformed individuals were recorded.

\section{Histopathological Studies:}

Adult females of Schistocerca gregaria were prepared for electron microscopy. The insects were killed by twisting of the head to break the neck membrane. The posterior tip of the abdomen was cut off and the head, with the gut attached, was removed. The carcass was cut open ventrally and the fat body overlying the flight muscles was removed with tissue paper.

Flight muscles were dissected in ice-cold (0-5 $\left.{ }^{\circ} \mathrm{C}\right)$ karnovsky fixative, pH 7.3 (Karnovsky, 1965). The tissues were transferred to fresh ice-cold fixative for $1 \mathrm{~h}$. After washing for 30 min in $0.1 \mathrm{M}$ sodium cacodylate buffer, $\mathrm{pH} \mathrm{7.3,} \mathrm{the} \mathrm{tissues} \mathrm{were} \mathrm{post-fixed} \mathrm{for}$ further $1 \mathrm{~h}$ in $1 \%$ osmium tetroxide in $0.1 \mathrm{M}$ sodium cacodylate buffer, $\mathrm{pH} 7.3$ at $4{ }^{\circ} \mathrm{C}$ (Brissanet al., 1996).
The muscles were dehydrated at room temperature via a graded series of ethanol solutions to propylene oxide prior to embedding in Araldite epoxy resin. Semithin sections were cut from these blocks (stained with toluidine blue) and examined by the light microscope (Spnrr, 1969).

Ultrathin sections obtained from selected blocks were mounted on copper grids stained with uranyl acetate and lead citrate and then examined with Joel 1010 transmission electron microscope (Reynolds, 1963) at the central laboratory, Faculty of Science, Ain Shams University.

\section{RESULTS \\ Toxicity Evaluation:}

Results in Table (1) and graphically illustrated in Figure (1) show the effects of Lufenuron on the one day old $5^{\text {th }}$ nymphal instar of $S$. gregaria during feeding technique.

Data cleared that the percentages of nymphal mortality of the $5^{\text {th }}$ nymphal instars of $S$. gregaria were $0.0,12.33$ and $21.01 \%$ after one day treatment with 50,75 and $100 \mathrm{ppm}$ of Lufenuron, respectively compared to control $(0.0 \%)$, whereas, the percentages of adult malformed were $89.99,73.34$ and $72.33 \%$, respectively compared to control $(0.0 \%)$. While the percentage of adult emergency was $10.0,0.0$ and $0.0 \%$ for the three concentrations, respectively. On the other hand, the percentage of total inhibition adult emergence was 90, 100 and $100 \%$ for the Lufenuron concentrations compared to control $(0.0 \%)$.

Statistical analysis in Table (1) shows highly significant differences among Lufenuron concentrations compared to control in \% nymphal mortality, and percent malformed adults after one day old of the $5^{\text {th }}$ nymphs of $S$. gregaria treatments $(\mathrm{F}=$ 
370.74 , and $127.01 \& \mathrm{LSD}=0.96$, and

$0.43)$, respectively.

Table (1): Biological activities of Lufenuron against 1 day old of the $5^{\text {th }}$ nymphal instar of schistocerca gregaria using feeding technique.

\begin{tabular}{|l|c|c|c|c|}
\hline Conc. (ppm) & $\begin{array}{c}\text { \% Nymphal } \\
\text { mortality } \\
\text { Mean } \pm \text { SE }\end{array}$ & $\begin{array}{c}\% \text { Malformed } \\
\text { adult } \\
\text { Mean } \pm \text { SE }\end{array}$ & $\begin{array}{c}\text { \% Adult } \\
\text { emergence } \\
\text { Mean } \pm \text { SE }\end{array}$ & $\begin{array}{c}\text { \%Total inhibition } \\
\text { of adult } \\
\text { emergence } \\
\text { Mean } \pm S E\end{array}$ \\
\hline Control & $0.0 \pm 0.0$ & $0.0 \pm 0.0$ & $100 \pm 0.0$ & $0 \pm 0.0$ \\
\hline $\mathbf{5 0}$ & $0.0 \pm 0.0$ & $89.99 \pm 0.0$ & $10.0 \pm 0.0$ & $90 \pm 0.0$ \\
\hline $\mathbf{7 5}$ & $12.33 \pm 0.33$ & $73.34 \pm 0.30$ & $0.0 \pm 0.0$ & $100 \pm 0.0$ \\
\hline $\mathbf{1 0 0}$ & $21.01 \pm 1.0$ & $72.33 \pm 0.33$ & $0.0 \pm 0.0$ & $100 \pm 0.0$ \\
\hline F 0.05 & $370.74 * * *$ & $127.01 * * *$ & - & - \\
\hline LSD & 0.96 & 0.43 & - & - \\
\hline
\end{tabular}

F: Measurement of distance between individual distributions

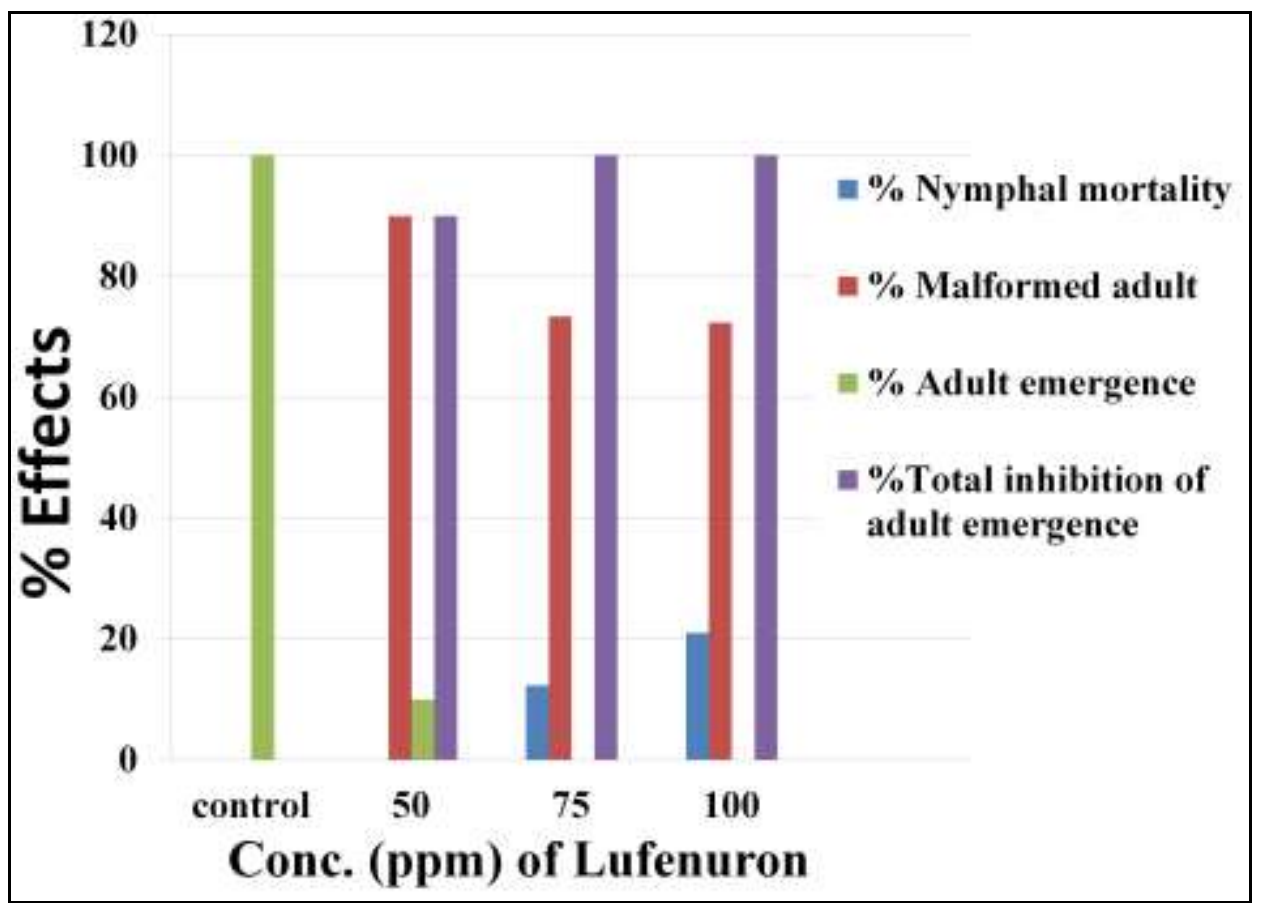

Fig. (1): Effect of Lufenuron on some biological aspects of the desert locust (S. gregaria) nymphs treated as 1-day old of the $5^{\text {th }}$ nymphal instar.

\section{Ultrastructure Study of Lufenuron} on $S$. gregaria:

Histopathological effects induced by different concentrations of Lufenuron were studied in adult muscles treated as $5^{\text {th }}$ nymphal instar of $S$. gregaria. These effects were illustrated in figures (2-6) and explained as follows:

Muscles of Untreated Adult Stage:

Ultrastructure of muscles of untreated adult $S$. gregaria was shown 
in Figures $(2 \& 3)$. The contractile fibrils that filled the cytoplasm of each large fiber demonstrate their patterned organization.

The muscle fibers having a radial arrangement of strap-like myofibrils separated from each other by mitochondria and with peripheral nuclei. Myofibrils were surrounded by an extensive sacroplamic reticulum which formed dyad connections.

The fine structure of myofibrils revealed the presence of at least two kinds of filaments in the fibrils. The fibrils are clearly constructed of filaments and the distribution of those filaments is related to the alternating light and dark bands.

From the several bands in the striation pattern, the Z-line is commonly selected as marking the limits of the sarcomere. This line is comparatively denser, especially in contracted fibrils, and may be correctly regarded as a kind of septum that is continuous transversely across the fibril. Other bands are: isotropic band
I, is bisected by the Z-line and anisotropic, A, is the more dense and is bisected by the narrow light band $(\mathrm{H}$ band). The ultrastructure of muscle fibers from mature locust was clearly showed myofibrils which had regular appearance and were, at the level of the A-band, clearly defined by surrounding sarcoplasmic reticulum. Mitochondria appear as spherical or oval shaped organelle. Each mitochondrion was delimited by an outer membrane and inner membrane. The inner membrane was folded to form cisternae in various directions.

\section{Muscles of Adult Treated with Lufenuron::}

Treatment of adults muscles in desert locust with Lufenuron showed distribution and disintegration of the fibers of these muscles in electron micrograph of longitudinal section, were the bands and zones less defined. I bands became like grid interspersed other components of fibers. Whereas mitochondria that are distinct (Fig 4, 5 \& 6).

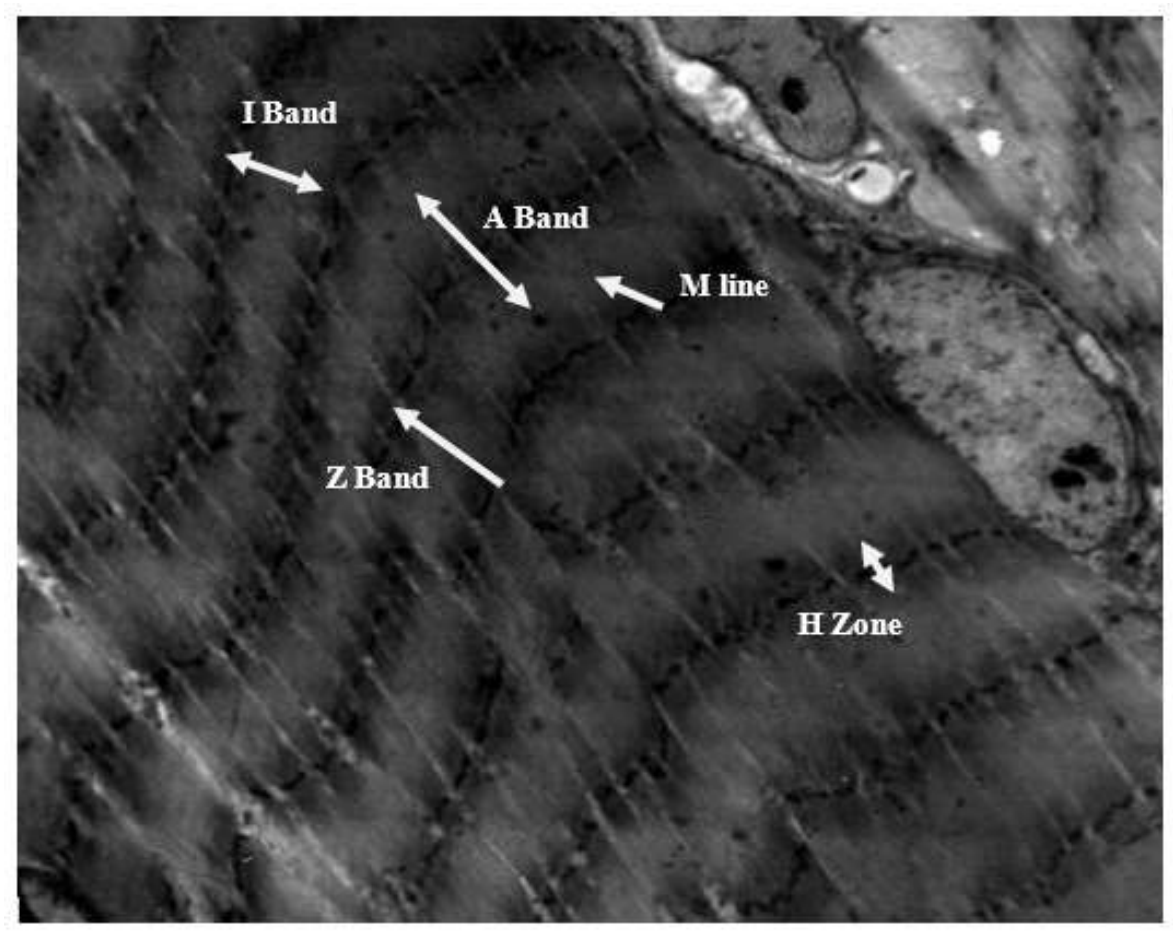

Fig. 2: Electron micrograph of longitudinal section through myofibrils of untreated adult Schistocerca gregaria showing fine structure of muscle 


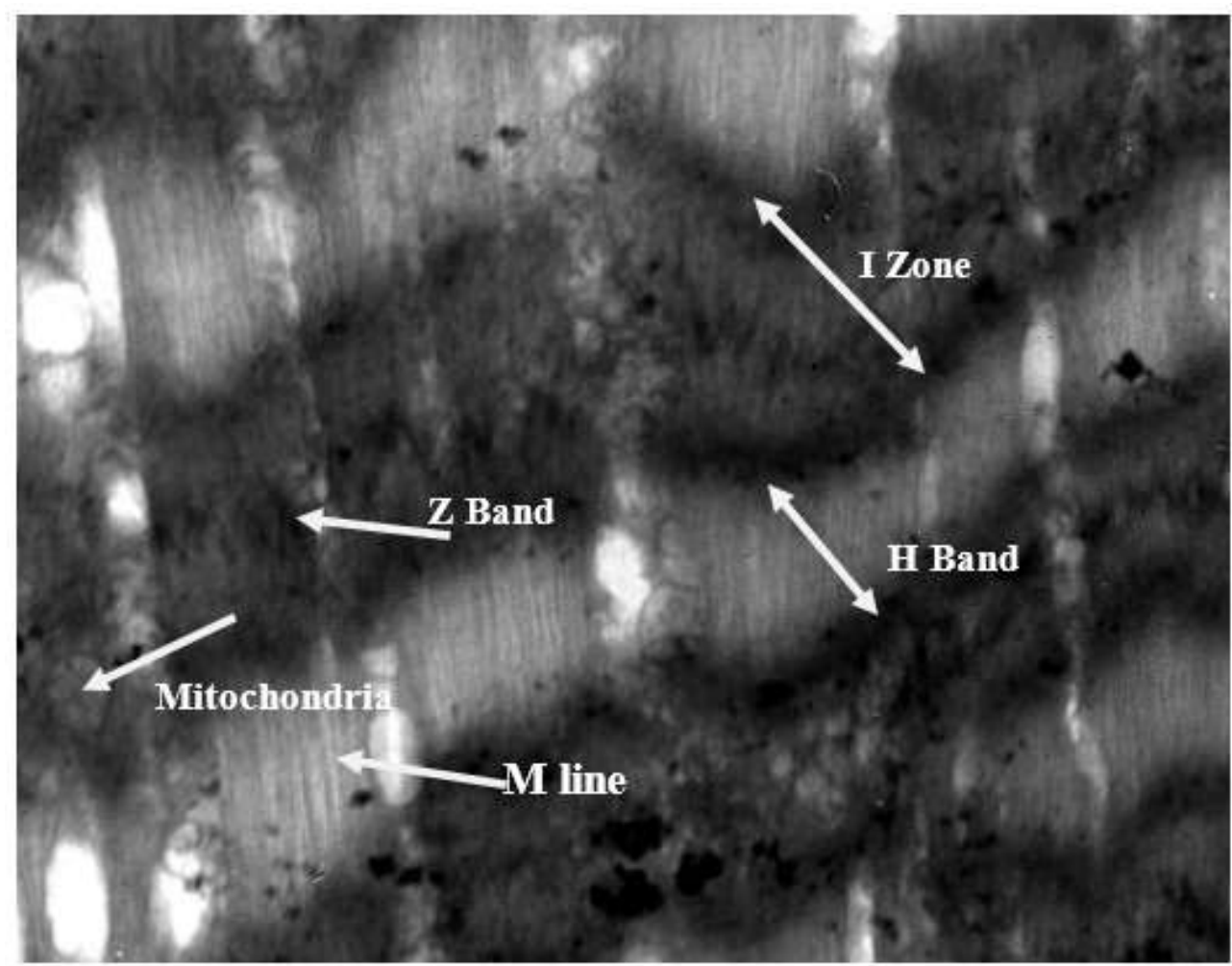

Fig. 3: Electron micrograph of longitudinal section through myofibrils of untreated adult Schistocerca gregaria showing M-line (Z), I, and H -bands of sarcomere and mitochondria

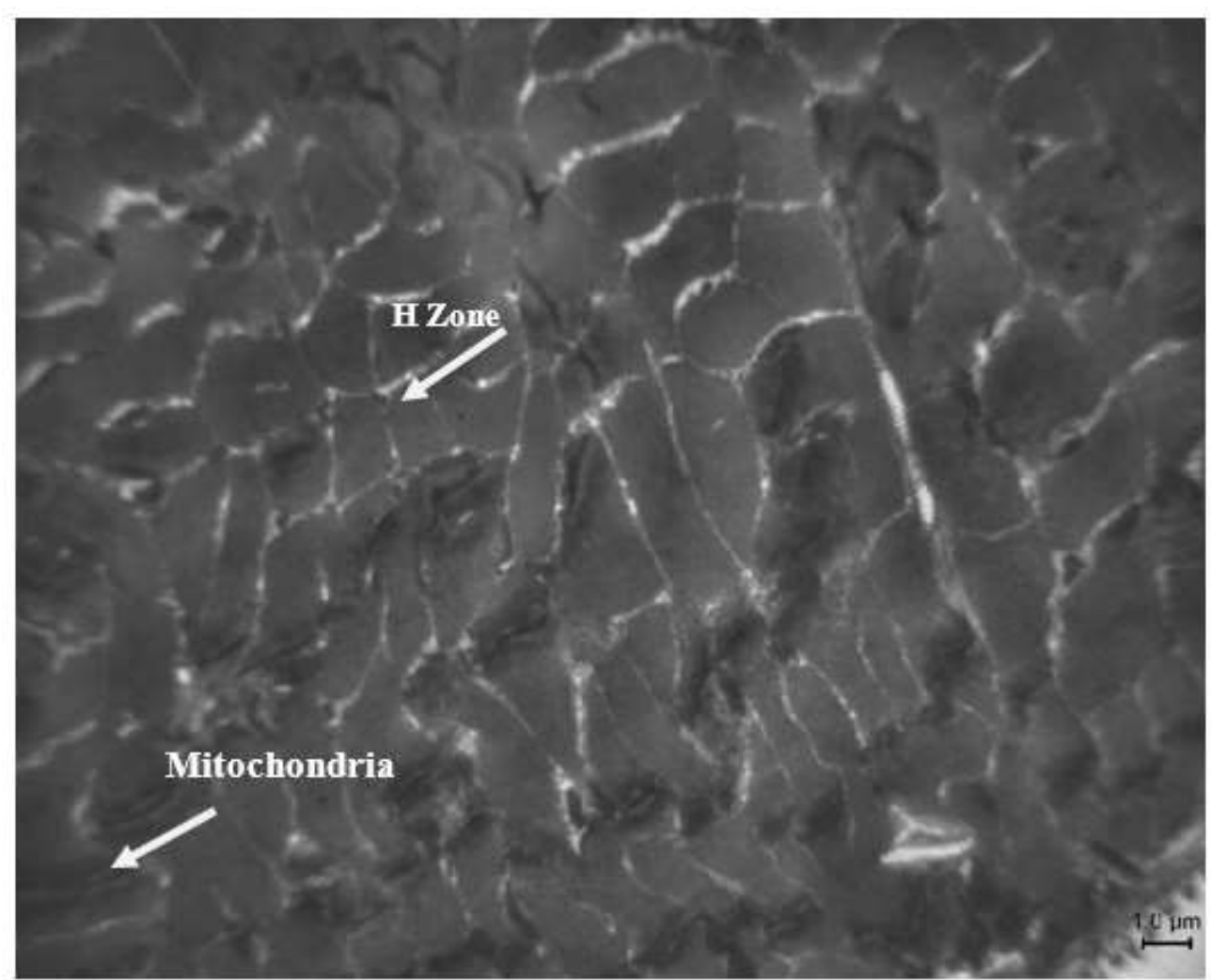

Fig. 4: Electron micrograph of longitudinal section through myofibrils of adult Schistocerca gregariatreated with Lufenuron showing less clear (Z), I, and H bands of sarcomere and mitochondria. $X=4000 . b m p$ 


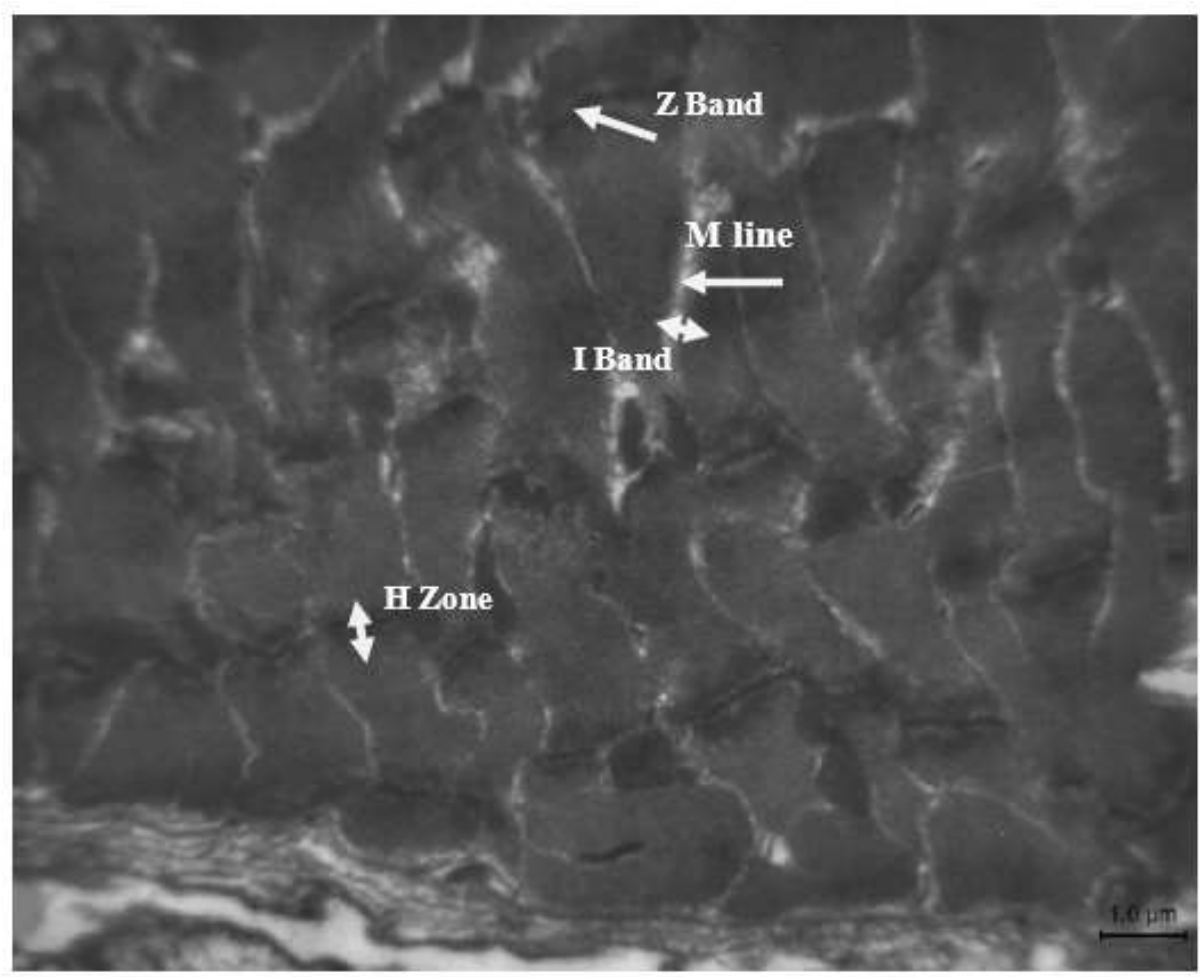

Fig. 5: Electron micrograph of longitudinal section through myofibrils of adult Schistocerca gregariatreated with Lufenuron showing $\mathrm{M}$ line (Z), I, and H bands of sarcomere. $X=8000 . b m p$

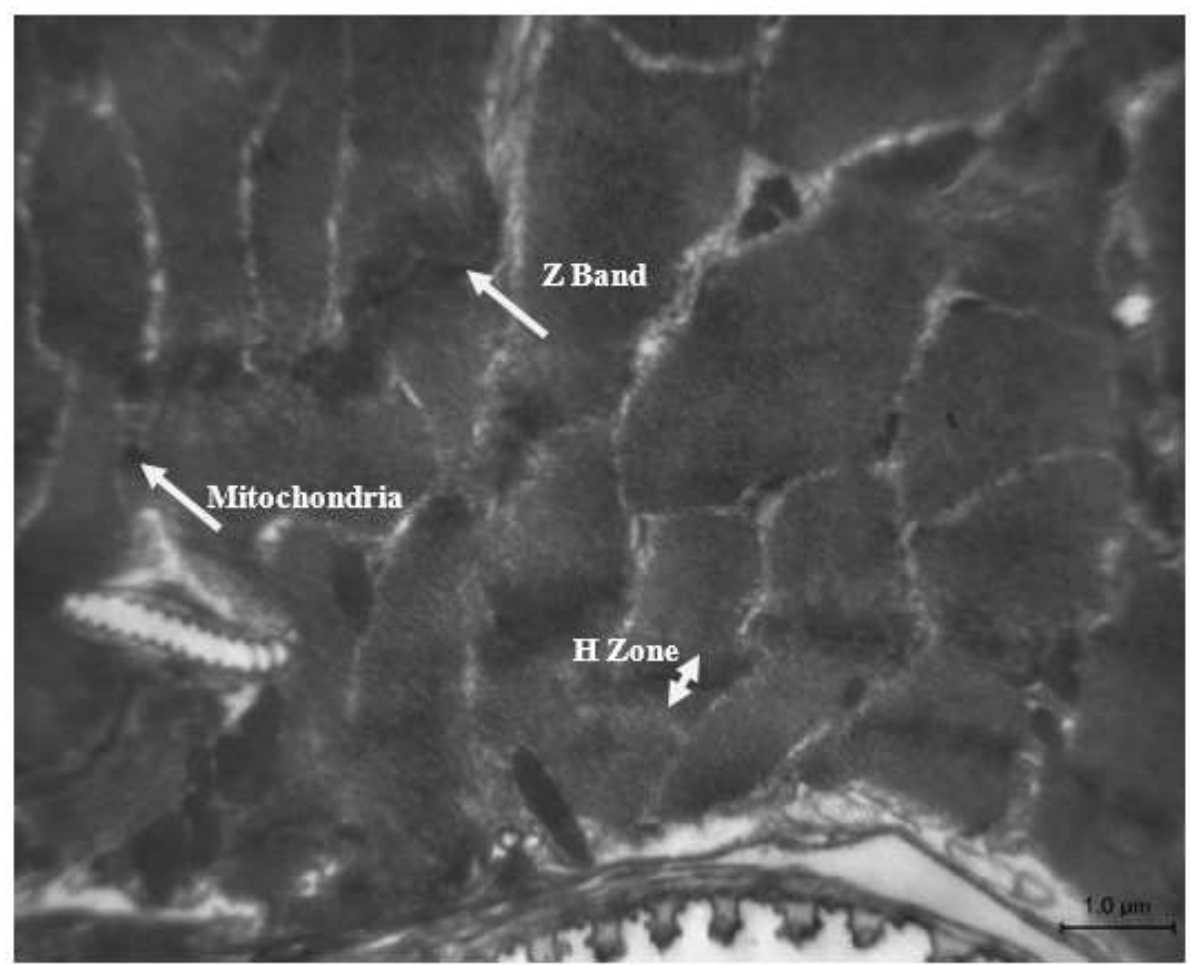

Fig. 6: Electron micrograph of longitudinal section through myofibrils of adult Schistocerca gregariatreated with Lufenuron showing (Z), I, and $\mathrm{H}$-bands of sarcomere and mitochondria. $\mathrm{X}=10000 . \mathrm{bmp}$ 


\section{DISCUSSION \\ Toxicological Studies:}

The present investigation revealed that, the treatment with insect growth regulators has toxic effects on the desert locust, Schistocerca gregaria. These effects depended on the concentrations of the compound and the age of the treated insects. In the present study, Lufenuron acted as chitin synthesis inhibitor (CSI), was used against the $5^{\text {th }}$ nymphal instar of S. gregaria during one day by feeding technique. The present study showed that, the treatment with different concentrations against one day old of the $5^{\text {th }}$ nymphal instar of $S$. gregaria caused nymphal mortality and failure to ecdysis to adult increased with the increase of Match concentrations. Also, the percentage of total inhibition of adult emergence reached to $100 \%$. More or less, the present results are agreed with those finding by several chitin synthesis inhibitors against the same acridide species, S. gregaria such as Diflubezuron, which interfered with the chitin synthesis during the nymphal ecdysis to the last instar causing some mortalities (Taha and El-Gammal, 1985), also Diflubenzuron when injected to the $5^{\text {th }}$ nymphs of $S$. gregaria was observed that, some treated instars were unable to moult and died without completing the moulting process, some were able to split the old cuticle but unable to wriggle out of the exuvia, some were able to complete moulting process but the resulting adults were deformed to varying degrees and some were able to moult without deformity in the resulting adults (Roa and Mehrotra, 1986), Pyriproxyfen when injection to last-nymphal instar of Locusta migratoria induced malformations of the wings and green pigmentations (Kort et al. 1991), the greatest mortality was recorded during ecdysis of early the $4^{\text {th }}$ nymphal instar to the $5^{\text {th }}$ nymphal instar of $S$. gregaria when treated with Chlorfluazuron (Abo ElEla et al.,1993), also Chlorfluazuron induced appreciable failure in ecdysis to adult stage when applied on the last nymphal instar (El-Gammal et al., 1993), Coppen and Jepson 1996a) when treated the 2nd nymphal instars of S.gregaria with Diflubenzuron, hexaflumuron and Teflubenzuron, they recorded mortality after all other treatments. Triflumuron caused different mortalities after 5 to 15 days of the barrier application in Mauritania (Wilps and Diop, 1997). Diflubenzuron and Teflubenzuron caused abortive moult, and most survivors developed twisted wings (Wakgari 1997), also, Lufenuron exhibited an inhibitory effect on the adult emergence after treatment of last instar nymphs, regardless of the timing of treatment ( Bakr, R.F. et al. 2008). When treated the newly moulted last $5^{\text {th }}$ instar nymphs of the desert locust Schistocerca gregaria with pyriproxyfen (juvenoid), tebofenozide (ecdysone agonist) and lufenuron (chitin synthesis inhibitor) an inhibitory action on haemolymph proteins was generally exhibited by all these IGRs along the nymphal stage with an exception of the day after treatment (1-day old nymphs) (Ghoneim, et al 2012).

\section{Histopathological Studies:}

The current study showed that the toxic effects of growth regulators when treated of Schistocerca gregaria by Lufenuron on tissues. The Lufenuron caused malfunction and decomposition of the components in the muscles of the desert locust. More or less, the present study are agreed with those finding by several insect growth regulators against same species, Schistocerca gregaria such as deltaphilanthotoxin (delta-PTX) of the 
venom from the wasp Philanthus triangulum blocks transmission postsynaptically at excitatory synapses on locust muscle. delta-PTX depresses both the iontophoretic glutamate potential and the excitatory junctional current (e.j.c.) in a glutamate receptor activation-dependent manner (Clark,et al 1982), also exposed newly moulted $4^{\text {th }}$ nymphal instars of Schistocerca gregaria in the laboratory to precocene II at $20 \mu \mathrm{g} / \mathrm{cm}^{2}$ or treating them topically with Cyclocheximide at 10 $\mu \mathrm{g} /$ locust and these reduced the respiratory rate of the flight muscles (Salem, et al 1982a), the effect of juvenile hormone $(\mathrm{JH})$ on the process of tracheolization of the dorsolongitudinal flight muscles of the migratory locust is studied during larval flight muscle development and used two treatments of precocene (20 $. \mathrm{mg} / \mathrm{cm}^{2}$ ) by contact method and cycloheximide (10 .mg/insect) by topical application on the newly moulted fourth instar nymphs that depressed the respiratory rate of flight muscles (Abdel Hamid M, 1982), GABA and the trans isomer of 4aminocrotonic acid were equally potent at inducing increases in $\mathrm{Cl}$ conductance when applied to distal extensor tibia muscle fibres of the locust (Schistocerca gregaria) (Scott, and Duce; 1985). No Fabp, however, was found in last instar nymphs, methoprene induced supernumerary nymphs and azadirachtin induced over-aged nymphs (Chen, et al 1993), (Mutwally, 1993) reported that tyramine alone was un effective on the foregut muscle, suggesting a lack of either pre- or postsynaptic receptors responding exclusively to this monoamine, The mitochondrial portion of the tissue enlarged from 17 to $30 \%$. Similar growth of all components was observed in precocious adults, obtained after treatment of 3rd-instar nymphs with ethoxy-precocene (Wang, Z; et al1993), (Blau, and Wegener; 1994) injected the biogenic amine octopamine into the haemolymph of 20-days old male locusts,Locusta migratoria, and the content of fructose 2,6-bisphosphate, a potent activator of glycolysis, was measured in the flight muscle after various time.the effect of the endogenous FMRFamide-like neuropeptide SchistoFLRFamide on the heart and skeletal muscle of Schistocerca gregaria (Robb, Sandra; et al1994), the effects of philanthotoxin-343 (PhTX-343; tyrosyl-butanoyl-spermine) and photolabile analogues of this synthetic toxin on locust (Schistocerca gregaria) skeletal muscle (Sudan, et al 1995), the effects of ryanodine, 9, 21didehydroryanodine and 9, 21didehydroryanodol on channels of skeletal muscles that are $\mathrm{K}^{+}$channel; a maxi, $\mathrm{Ca}^{2+}$-activated $170 \mathrm{pS}$ channel (BK channel) and an inward rectifier of $35 \mathrm{pS}$ conductance (IK channel) (Vais,et al 1996). The juvenile hormone $(\mathrm{JH})$ was assessed by comparing muscle properties in immature and mature females and showed that $\mathrm{JH}$ production was inhibited by allatectomy early in adult life (Rose, (2004), the inhibitory innervation of the intersegmental (body wall) muscles between the first and the second thoracic segment of the migratory locust, Locusta migratoria, which investigated using neuroanatomical, immunocytochemical and electrophysiological techniques (Braunig, P; et al 2006), Ttebufenozide treatments affected the ultrastructural configuration of thoracic muscles (Ghoneim; et al 2018), Flufenoxuron caused several dangerous effects on the thoracic muscles such as distortion shape of the $\mathrm{Z}$ line and disorganization of $\mathrm{A}, \mathrm{I}$ and $\mathrm{H}$ bands (Bakr, R.F; et al (2008), showed that the effects of a methanolic extract of the 
plant Haplophyllum tuberculatum (ME-Ht) and of Teflubenzuron (TFB) which compared on several reproductive variables and ecdysteroid titers in the females of Locusta migratoria.

\section{REFERENCES}

Abbassi K.; Zineb A. and Ghaout, S. (2003): Biological effects of alkaloids extracted from: Three plants of Moroccan avid areas on the desert locust. J. Physiol. Entomol., 28: 232-236.

Abdel-Hamid, M., Salem, M S.; Eid, M. A.; El-Ibrashy, M T.; (1982): Effect of precocene ii and cycloheximide on flight and coxal muscles respiratory metabolism in the desert locust Schistocerca gregaria. Bulletin of the Entomological Society of Egypt Economic Series (13): 117-126.

Abou El-Ela, R.G. (1993): Morphometric and morphogenetic aberrations induced by the IGR Chlorfluazuron (IKI) and two formulations of Triflumuron in Schistocerca gregaria Forsk. Bull. Ent. Soc., Egypt, Econ.Ser., 20: 217-227.

Bakr, R.F.A. (1986): Morphogenic and physiological aberration induced by certain IGRs in the house fly Musca domestica. Unpublished Ph.D. Thesis, Ain Shams Univ. Cairo, Egypt.

Bakr, R.F.A.; Isa, A.M.; Gabry, M.S. and Guneidy, A.M. (1997): Histopathological changes in Culex pipiens (Diptera: Culicidae) induced by juvenile hormone mimics. J.Egypt.Ger.Soc.Zool., 22(E): 27-45.

Bakr, R.F.Ghoneim, K.S.; Al-Dali, A.G.; Tanani, M.A. and Bream, A.S.(2008) : Efficiency of the chitin synthesis inhibitor lufenuron (cga-184699) on growth, development and morphogenesis of Schistocerca gregaria (orthoptera: acrididae): Egypt. Acad. J. biolog. Sci., 1 ( 1) 41- 57.

Blau, C; and Wegener, G,(1994): Metabolic integration in locust flight: the effect of octopamine on fructose 2,6-bisphosphate content of flight muscle in vivo Journal of Comparative Physiology B1994, Volume 164, Issue 1, pp 11-15.

Braunig, P; Schmh, M; and Wolf, H, (2006): Common and specific inhibitory motor neurons innervate the intersegmental muscles in the locust thorax. Journal of Experimental Biology: 1827-1836.

Brissan, A.; Gharibian, S.; Agen, R.; Leclerc, D.F. and Breuil, C. (1996): Localization and characterization of the melanin granules produced by the sapstaining fungus Ophiostoma piceae. Material and Organismen, 30:23-32.

Chen, X.; Wang, Z. and Haunerland, N. H. (1993). Light muscle fatty acid binding protein synthesis in juvenile and adult forms of desert locust. Insect Biochem. Molec. Biol., 50 (3) : 183 - 195

Clark, R. B; Donaldson, P. L; Gration, K. A; Lambert, J. J; Piek, T; Ramsey, R; Spanjer, W; Usherwood, P. N; (1982): Block of locust muscle glutamate receptors by delta-philanthotoxin occurs after receptor activations: Brain Research (Impact Factor: 2.88). 07/1982; 241(1):105-14.

Clark, L.; Tempale, G.H.R. and Vincent, J.F.V. (1977): The effects of chitin inhibitor Dimilin on the production of peritrophic membrane in locust, Locusta migratoria. J. Insect Physiol., 23 : 241-246.

Coppen, G. D. A. and Jepson, P. C. (1996a):The effects of the duration of exposure on the toxicity of 
diflubenzuron, hexaflumuron and teflubenzuron to various stages of II instar Schistocerca gregaria. Pesticide Sci.; 46 (2): 191-197.

De Cock, A. and Degheele, D. (1991): Cytochemical demonstration of chitin incorporation in the cuticle of Trialeurodes vaporariorum (West Wood) (Homoptera : Aleyrodidae) buprofezin treatment. Int. J. Insect Morphol. Embryol., 22(2-4): 119-125.

DeLoach, J.R.; Meola, S.M.; Mayer, R.T. and Thompson, J.M. (1981): Inhibition of DNA synthesis by diflubenzuron in pupae of the stable fly Stomoxys calcitrans (L.) Pest. Biochem. Physiol., 15:172.

Deul, D.J.; de Jong, B.J. and Kortenback, J.A.M. (1978): Inhibition of chitin synthesis by two 1-(2,6-disubstituted benzoyl)3-phenylurea insecticides. Pest. Biochem. Physiol., 8 : 98-105.

Dirsh, V. M. (1974): Genus Schistocerca (Acridomorpha, Insecta). The Hague, The Netherlands: W. Junk.

El-Gammal, A. M.; Osman, M. A.; Shaban, O. A. and Badawy, N. S. (1993): The role of anti-chitin synthesis, chlorfluazuron (IKI) on the main metabolites during metamorphosis of Schistocerca gregaria Forsk. Egyption J. Agric. Res., 71 (4): 891-899.

Ghoneim KS, Abdel-Khaliq AA, Bream AS, Emam DM (2012 a). Food preference and consumption by adults of black blister beetle Meloe proscarabaeus (Coleoptera: Meloidae) on different host plants. Int. J. Agric. Sci. Res., 1(2):16-23.

Ghoneim K. and Reda F.A. Bakr (2018): Physiological activities of anti-juvenile hormone agents against insects and their role for devising fourth generation insecticides: A Comprehensive Review. Egypt. Acad. J. Biolog.
Sci. (A. Entomology) Vol. 11(3)pp: 45- 138

Gijswijt, M.J.; Deul, D.H. and DeJong, B.J. (1979): Inhibition of chitin synthesis by benzoylphenylurea insecticides, III. Similarity in action in Pieres brassicae (L.) with polyxin D. Pestic. Biochem. Physiol., 12:84-94.

Hammock, C.D. and Quisted, G.B. (1981): Meabolism and mode of action of juvenile hormone, juvenoids and other insect growth regulators. In "Progress in pesticide Biochemistry" (Hutson, D.H. and Roberts, T.R. eds.), Vol. 1, pp. 1-85, John Wiley \& Sons Ltd.

Ishaaya, I. and Ascher, K.R.S. (1977):

Effects of Diflubenzuron on growth and carbohydrate hydrolases of Tribolium castaneum. Phytoparasitica, 5:149-158.

Karnovsky, M.J. (1965): The localization of cholinesterase activity in rat cardiac muscle by electron microscopy. J. Cell. Biol. 23, 217-232.

Kort, C. A. D.; Koopmanschop, A. B. and De Kort, C. A. D. (1991): A juvenile hormone analogue affects the protein pattern of the haemolymph in last instar larvae of Locusta migratoria (Bibliographic citation). J. Insect physiol., 87-93.

Mutwally, H.M.A. (1993): The effect of some biogenic amines on the spontaneous activity of locust (Locusta migratoria) fore- and hindgut visceral muscles. Journal of Egypt German Society Zoological Comparative Physiology. 11 (A): 47-56.

OECD (2004): The Desert Locust outbreak in West Africa, Retrieved from http://en:wikipedia. org/w/ index. php? Title $=$ Desert Locust $\&$ Oldid $=516773002$ categories .

Parween, S. (1997): Effect of triflumuron on the adult mid gut of Tribolium castaneum (Herbst.) 
(Coleoptera : Tenebrioidae). Univ. J. Zool. Rajshahi Univ., 16:11-18.

Pelsu, F.W. (1985): Histopathological effects of two insect chitin inhibitors in the alimentary canal of chironomid midges (Diptera: Chironomidae). Bull.Soc.Vector Ecol., 10(2): 72-89.

Reynolds, S.E. (1963): The use of lead citrate at high $\mathrm{pH}$ as an electron opaque stain in electron microscopy. J. Cell Biology, 1:208.

Rao, P.A. and Mehrotra, K.N. (1986):

Toxicity of Diflubenzuron to

Schistocerca gregaria Forsk. Indian

J. Entomol., 48 (4): 474-477.

Robb, S.; Evans, and Peter D., (1994):

The modulatory effect of schistoFLRFamide on heart and skeletal muscle in the locust Schistocerca gregaria. The Journal of Experimental Biology.7-42.

Rose, and Uwe, (2004): Morphological and functional maturation of a skeletal muscle regulated by juvenile hormone. Journal of Experimental Biology uary; 207(3): 483-495.

Saad, A.S.A.; Lahny, M.H.E.; Awad, H.A.; Radwan, H.A. (1985): Histopathological studies of certain pesticides on pink bollworm Pectinophora gossypiella. Proc0 $6^{\text {th }}$ Arab Pest. Conf., Tanta Univ., Egypt, 1:7791.

Salama, H.S.; Motagally, Z.A. and Skatulla, U. (1976): On the mode of action of Dimilin as a moulting inhibitor in some lepidoptrous insects. J. Appl. Entomol., 80:396-407.

Salem, M. S.; Eid, M. A.; El-Ibrashy, M. T. and Abdel- Hamid, M. (1982a): Effect of precocene II, Cycloheximide on flight and coxal muscles respiratory metabolism in the adult desert locust,
Schistocerca gregaria Forsk. Bull. Entomol. Soc. Egypte, Econ. Ser., 1982/1983, (13):117-125.

Scott, R. H. and Duce, I. R. (1985), Effects of 22,23dihydroavermectin $\mathrm{B}_{1 \mathrm{a}}$ on locust (Schistocerca gregaria) muscles may involve several sites of action. Pestic. Sci., 16: 599-604.

Siddall, J.B. (1976): Insect growth regulators and insect control: A critical appraisal. Environ. Health Press.14: 119-126

Spnrr, A.R. (1969): A low viscosity epoxy resin embdding medium for electron microscopy. J. Ultrastruc. Res., 26:31-43.

Sudan, H. L.; Kerry, C. J.; Mellor, I. R.; Choi, S.K.; Huang, D.; Nakanishi, K.; Usherwood, P. N. R., (1995): The action of philanthotoxin-343 and photolabile analogues on locust muscle. Invertebrate Neuroscience. 1(2): 159-172.

Taha, G. Z. and El-Gammal, A. M. (1985): Laboratory evaluation of diflubenzuron against the $4^{\text {th }}$ nymphal instar of Schistocerca gregaria. First Int. Conf. Appl. Sci., Zagazig Univ., IV: 269-278.

Taha, G. Z. and El-Gammal, A. M. (1990): Morphogenetic effects of non-terpenoid juvenile hormone analogue, S-31183 on, metamorphosis of last nymphal instar of Schistocerca gregaria. Egyptian J. Appl. Sci., 5: 75-81.

Tarai S, Doumandji S (2009): Advance in environmental Biology. 3 : 3:308 retrievedwww.connection .ebscohost.com/c/articles.

Uvarov, B. P. (1977): Grasshopper and locust Vol II. Centre for overseas pest research London. 80 - 95 .

Vais, H.; Rucareanu, C.; Usherwood, P. N. R., (1996): Ryanoids change the permeability of potassium channels of locust Schistocerca gregaria muscle.Pfluegers Archiv 
European Journal of Physiology 432(4): 700-707.

Verloop, A. and Ferrel, C.D. (1977):

Benzoylureas - a new group of larvicides interferring with chitin deposition. In "Pesticide chemistry in the $20^{\text {th }}$ Century" (Plummer, J.R., ed.). Acs symposium series 37, pp: 237270, Whashington, D.C., Amer. Chem.Soc.

Wakgari, W. (1997): A comparison of efficacies of bran-based baits containing diflubenzuron, teflubenzuron, and fenitrothion against desert locust, Schistocerca gregaria F. International J. Pest Manag., 43 (2): 163-167.

Wang, Z.; Chen, X. and Haunerland, N. H. (1993): Flight muscle development in juvenile and adult forms of the desert locust,
Schistocerca gregaria. J. Insect Physiol, 39 (4): 325-333.

Wilps, H. and Diop, B. (1997): The effects of the insect growth regulator Triflumuron (Alsystin) on hopper bands of Schistocerca gregaria. International J. Pest Manag., 43 (1): 19-25.

Younes, M.W.F.; Abou El-Ela; R.G. and El-Mhasen, M.A. (2000): Histopathological effects of some insecticides on the larval midgut and integument of the lesser cotton leafworm Spodoptera exigua (HB) (Lepidoptera : Noctuidae). J. Egypt Ger. Soc. Zool., 32:19-31.

Yu, S.J. and Terrier, S.S. (1977): Ecdysone metabolism by soluble enzymes from three species of Diptera and inhibition by the insect growth regulator TH-6040. Pest. Biochem. Physiol., 7:48-55. 